\title{
Assessment of hand function after successful replantation of upper limb at arm
}

\author{
V. Koteswara Rao Rayidi, Venkata Bhargava Velde, Narsimha Rao, N Ram Babu, Laxman Sambari \\ Department of Plastic Surgery, Nizam's Institute of Medical Sciences, Hyderabad, Telangana, India
}

Address for correspondence: Dr. Venkata Bhargava Velde, Department of Plastic Surgery, Nizam's Institute of Medical Sciences, Hyderabad, India. E-mail: dr.vvbhargava@gmail.com

\section{ABSTRACT}

In upper arm replantation, a successful anastomosis guarantees the viability and good quality repair determines the overall function of the hand. There is paucity of successful arm replantation case reports in the literature. This is a case report of a successful arm replantation in a four year child with a near total functional outcome. We have used different scores to assess the functional outcome.

\section{KEY WORDS}

Hand function; DASH score; upper arm replantation

\section{INTRODUCTION}

omplete experimental limb replantation was first published by Hopfner in 1903. MaH and McKhann in Boston reported the first successful replantation done in 1962, of arm of a 12-year-old boy.

Replantation at arm level is quite rare compared to amputations at a more distal level. A literature review of arm replantation reveals no significant studies on evaluation/restoration of function. There was no significant study on the assessment of hand function post major upper limb replantation. This is a case report, in which the post-operative recovery is nearly that of a normal hand, which makes it a unique one.

\begin{tabular}{|l|l|}
\hline \multicolumn{2}{|c|}{ Access this article online } \\
\hline Quick Response Code: & Website: \\
\hline & www.ijps.org \\
\cline { 2 - 2 } & \\
\hline
\end{tabular}

A viable replanted, though considered a success from the point of view of the surgeon, should indeed be considered a failure if the patient is unable to perform most of his or her activities of daily living (ADL) and depends on social

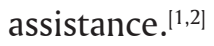

This is a case study of a 4-year old female child who presented to us with complete amputation of the right upper limb at proximal third level. We have used different scores to assess the return of hand function.

\section{PRESENTATION TO THE HOSPITAL}

The patient is a 4-year old female child who sustained traumatic amputation of right upper limb at proximal

This is an open access article distributed under the terms of the Creative Commons Attribution-NonCommercial-ShareAlike 3.0 License, which allows others to remix, tweak, and build upon the work non-commercially, as long as the author is credited and the new creations are licensed under the identical terms.

For reprints contact: reprints@medknow.com

How to cite this article: Rayidi VK, Velde VB, Rao N, Babu NR, Sambari L. Assessment of hand function after successful replantation of upper limb at arm. Indian J Plast Surg 2016;49:415-8. 


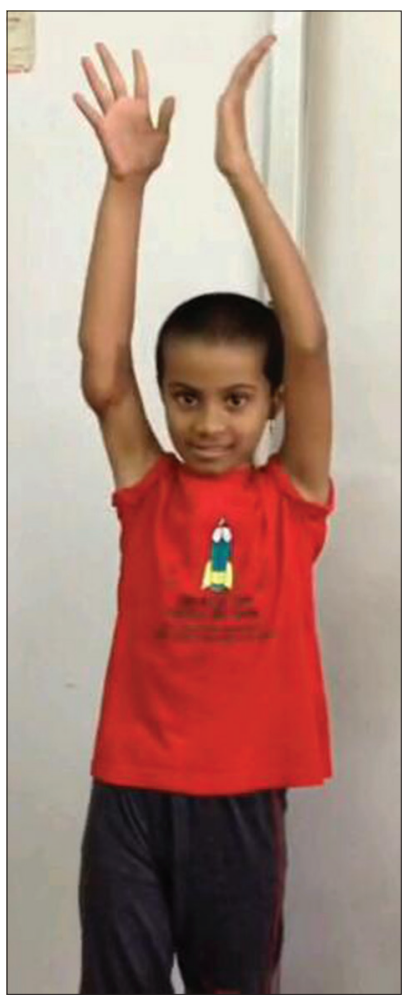

Figure 1: Demonstration of overhead shoulder abduction

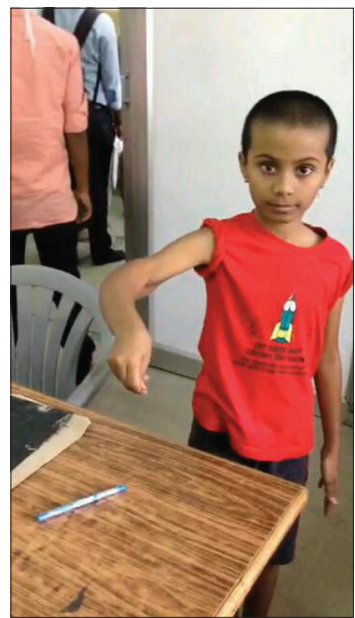

Figure 3: Demonstration of key pinch

third level due to slip from a train at around 8 am on $28^{\text {th }}$, October 2009 at Jangaon, nearly $100 \mathrm{~km}$ from our centre.

There were no other associated injuries.

The patient was immediately shifted to a local hospital nearby where the amputated part was well preserved. It was wrapped in a saline-soaked cloth placed in a polyethene bag and carried to the centre in an ice container. This patient had a mild avulsion injury with avulsion of nerves and muscles. The warm ischaemia time was approximately $20 \mathrm{~min}$.

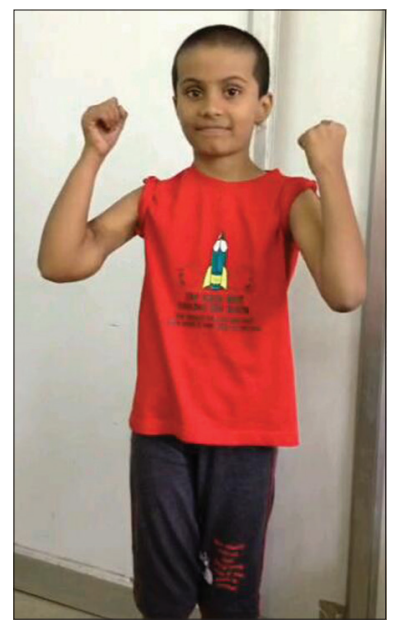

Figure 2: Demonstration of elbow and finger flexion

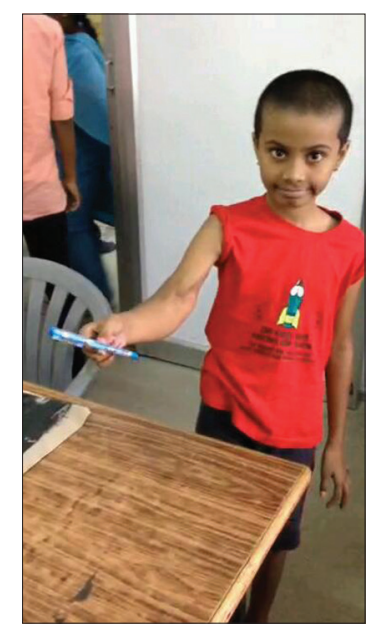

Figure 4: Demonstration of pincer grasp

\section{SURGICAL PROCEDURE}

The patient was taken for surgery within one hour of arrival to the hospital and it lasted for nearly $10 \mathrm{~h}$. The cold ischaemia was approximately $3 \mathrm{~h}$. No temporary shunts were done as the total ischaemia was much less than the tolerant levels of different tissues as the surgical team was able to restore circulation within the stimulated time. No fasciotomies were done.

The amputated part was manually squeezed from distal to proximal to squeeze out any remaining blood or microthrombi inside the vascular lumen and to assure patency of the vascular channels.

Debridement of the wound and shortening of the humerus were done. Fixation of humerus with plates and screws was done by orthopedicians. End-to-end anastomosis of brachial artery, cephalic vein and venae comitantes followed 


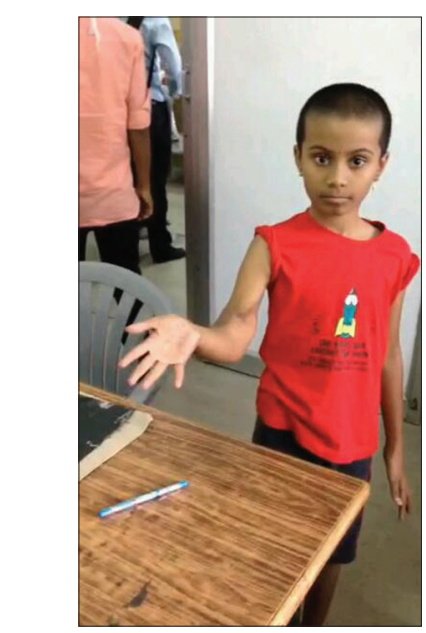

Figure 5: Demonstration of interossei function

by end-to-end repair of all musculature and coaptation of radial, ulnar and medial nerves.

There were no major complications, and the patient was discharged from the hospital on $9^{\text {th }}$, November 2009.

The patient needed an additional procedure on $27^{\text {th }}$, November 2009 for a small raw area on the arm and was grafted.

\section{REHABILITATION}

There is no standard protocol for rehabilitation following replantation surgeries. ${ }^{[3]}$ Every amputation is different, and the rehabilitation protocol after replantation must match the healing process of the limb ${ }^{[4]}$ The limb needs to be constantly re-evaluated for changes such as increased oedema, splint adjustments and the skin integrity need to be monitored to prevent tissue breakdown..$^{[5]}$

The elbow was splinted in flexion, wrist and hand in neutral. Two weeks post-replantation, the parents were instructed to passively flex and extend the fingers and wrist.

Physiotherapy of the elbow was started after the raw area over the arm settled.

We have followed Brigham and Women's Hospital generalised rehabilitation protocol, modified accordingly as per need. Range of motion exercises was started after 2 weeks.

The patient was closely monitored in the outpatient for progressive Tinel's sign along with galvanic stimulation as the muscles got reinnervated. ADL was encouraged as she gained strength in the muscles along with strengthening exercises. The patient regained total sensation by the end of 2 years.

\section{FINAL RESULTS}

This is the assessment made in August 2015 nearly 6 years after replantation.

We used the BMC grading of sensory and motor grading for assessment [Figures 1-5].

Sensation in median, ulnar and radial nerve was S4; Motor power in shoulder was M5 and elbow, wrist and was M4 to M5.

\section{Disabilities of arm, shoulder and hand score}

The disability of the arm, shoulder and hand (DASH) questionnaire is an upper extremity-specific outcome measure that was introduced by the American Academy of Orthopedic Surgeons in collaboration with a number of other organisations. ${ }^{[6]}$ The scores for all items are then used to calculate a scale score ranging from 0 (no disability) to 100 (most severe disability). The score for the disability/ symptom scale is called the DASH score.

DASH-disability/symptom score $=$ ([sum of $n$ responses] -1$) \times 25$ ( $n$ is equal to the number of completed responses)

The child has mild difficulty in writing.

So, the score comes to $\{(31 / 29)-1\} \times 25=1.724$

Considering the score, the child has a negligible amount of disability.

\section{Chen's criteria}

On Chen's grade, the patient scored grade I.

\section{Sollerman test}

Although Sollerman test was designed to give a good measure of overall function of the hand and not the elbow and shoulder, we have used in this study as its main purpose is to produce a true picture of grip function in ADL and to reflect the most common grips in daily life.

The test consists of twenty activities of daily living. The scoring rules were chosen so that patients of normal 
hand function would achieve 80 points with dominant hand and 77-79 points with the non-dominant hand.

The patient in our study scored $79 / 80$ as she had mild difficulty in writing and could not complete the task within 20 s scoring 3 out of 4 .

\section{CONCLUSION}

Upper extremity replantation should be a procedure within the realm of all plastic surgeons. The quality of the bone, tendon, nerve and skin repair determines the overall functional success of the replanted part. Repair of all structures should be attempted at the time of primary procedure as in this case, as secondary surgery is technically very difficult. A meticulously performed replantation along with monitored post-operative rehabilitation can result in a near total normal hand function.

\section{Declaration of patient consent}

The authors certify that they have obtained all appropriate patient consent forms. In the form the patient(s) has/ have given his/her/their consent for his/her/their images and other clinical information to be reported in the journal. The patients understand that their names and initials will not be published and due efforts will be made to conceal their identity, but anonymity cannot be guaranteed.

\section{Acknowledgement}

We thank Dr. R.Srikanth, Head of Department, Plastic surgery for his support in publishing this article.

\section{Financial support and sponsorship}

Nil.

\section{Conflicts of interest}

There are no conflicts of interest.

\section{REFERENCES}

1. Garner R. Upper limb replantation: Does the patient benefit? $\mathrm{Br}$ J Occup Ther 1988;51:228-31.

2. Russell RC, O'Brien BM, Morrison WA, Pamamull G, MacLeod A. The late functional results of upper limb revascularization and replantation. J Hand Surg Am 1984;9:623-33.

3. Papanastasiou S. Rehabilitation of the replanted upper extremity. Plast Reconstr Surg 2002;109:978-81.

4. Chan SW, LaStayo P. Hand therapy management following mutilating hand injuries. Hand Clin 2003;19:133-48.

5. Scheker LR, Hodges A. Brace and rehabilitation after replantation and revascularization. Hand Clin 2001;17:473-80.

6. Hudak PL, Amadio PC, Bombardier C. Development of an upper extremity outcome measure: The DASH (disabilities of the arm, shoulder and hand) [corrected]. The Upper Extremity Collaborative Group (UECG) Am J Ind Med 1996;29:602-8. 